\title{
A LITERATURA SOBRE CIDADES INTELIGENTES E O LUGAR DA DEMOCRACIA
}

\section{STUDIES ON SMART CITIES AND THE PLACE OF DEMOCRACY}

\author{
Wilson Levy ${ }^{1}$ \\ Rafael da Silva Carvalho \\ Caio Aloe $^{3}$ \\ Antônio Joelson Rodrigues Bezerra ${ }^{4}$
}

\section{RESUMO}

O presente artigo pretendeu identificar o lugar da democracia na literatura sobre as cidades inteligentes, segundo o pressuposto de que a política democrática representa uma forma inteligente de solucionar, segundo critérios institucionais e legais, as disputas que ocorrem no território. Para tanto, efetuou uma revisão sistemática de literatura (RSL), cujos resultados indicam um caminho ainda a ser percorrido para identificar uma relação forte entre um tema e outro. Com isso, buscou construir inferências a partir da aproximação de referências bibliográficas dos dois temas. $\mathrm{O}$ resultado apontou que há um enorme campo de possibilidades de análise sobre o assunto.

Palavras-chave: cidades inteligentes; democracia; revisão de literatura.

\section{ABSTRACT}

This article intended to identify the place of democracy in the literature on smart cities, according to the assumption that democratic politics represents an intelligent way of solving, according to institutional and legal criteria, disputes that occur in the territory. Through a Systematic Review, the results indicate a long way to identify a strong relationship between the themes. With this, it sought to build inferences from the approximation of bibliographic references of the two themes. The result pointed out that there is a huge field of analysis possibilities on the theme.

Keywords: smart cities; democracy; literature review.

\footnotetext{
${ }^{1}$ Doutor em Direito pela PUC-SP com estágio de pós-doutoramento em Urbanismo pela Mackenzie. Afiliação: Diretor e professor permanente do programa de pós-graduação em Cidades Inteligentes e Sustentáveis da UNINOVE. Orcid:https://orcid.org/0000-0002-8130-0288. E-mail:wilsonlevy@gmail.com

2 Mestre em Cidades Inteligentes e Sustentáveis pela UNINOVE. Afiliação:UNINOVE. Orcid:https://orcid.org/0000-0001-6310-1333. E-mail:rafascarvalho@gmail.com

3 Mestrando em Cidades Inteligentes e Sustentáveis pela UNINOVE.Afiliação:UNINOVE. Orcid:https://orcid.org/0000-0002-8229-4828. E-mail:caio.aloe.matos@gmail.com

${ }^{4}$ Graduando em Direito pela UNINOVE. Bolsista de iniciação científica - PIBIC-CNPq.Afiliação:UNINOVE. Orcid:https://orcid.org/0000-0001-6581-2091. E-mail:joelson.rodbez@gmail.com
} 


\section{INTRODUÇÃO}

A teoria democrática experimentou amplo desenvolvimento ao longo do século $\mathrm{XX}$. Cobrindo um arco de autores e abordagens que vai da tradição europeia, com Jürgen Habermas, Charles Taylor e outros, às manifestações decoloniais com sua variedade de abordagens e racionalidades, bem descritas por autores oriundos de diversas áreas do conhecimento e diversas tradições de pensamento, as perspectivas sobre a democracia são diversas.

Sua aplicação aos estudos urbanos é de fundamental importância como categoria apta a mediar de forma inteligente as disputas e conflitos típicos das formas de integração social nas cidades. O propósito do artigo, nesse sentido, é efetuar um levantamento de bibliografia científica para mapear, avaliar, identificar o território intelectual que relaciona os temas das cidades inteligentes e da democracia para a seguinte questão de pesquisa "Como a categoria 'democracia' se relaciona com o conceito de cidade inteligente?'”

A especificidade das cidades inteligentes está na raiz da pesquisa desenvolvida pelos dois mestrandos que subscrevem o presente artigo, que contou com a colaboração de um graduando bolsista de iniciação científica do PIBIC-CNPq. Por meio de Revisão Sistemática de Literatura (RSL) serão coletados na base de artigos científicos Scopus os termos, "smartcit*" AND "democrac*" OR "social participation" para demonstrar como os conceitos de democracia se relacionam com a temática de cidades inteligentes.

Em uma busca preliminar, não encontramos artigos de revisão sistemática de literatura com essa especificidade, por isso o artigo visa apresentar uma base de literatura para o aprofundamento da discussão de cidades inteligentes e democracia e como os conceitos se relacionam

\section{PARA COMEÇO DE CONVERSA: DEMOCRACIA E ESPAÇO URBANO, UMA APROXIMAÇÃO}

O espaço urbano como um local onde se manifesta a conflituosidade inata às formas organizadas de vida comunitária (SILVA NETO, 2016, p. 113) nos leva à necessidade de pensar num modelo capaz de mediar diferentes visões de mundo e organizar as disputas daí decorrentes. Como já desenvolvemos em outros trabalhos, a hipótese que partimos é a do modelo de democracia em que esses conflitos podem ser ponto do seu próprio desenvolvimento. 
Mas de qual democracia estamos falando? As possibilidades de escolha são vastas e se faz necessário conceituá-la para a formulação de caminhos da sua construção.

Uma visão da instituição pode ser um início para a definição de democracia. Utilizando o olhar de Joseph Schumpeter, a própria existência de um arranjo institucional como forma de tomada de decisão para alcance do bem comum é uma das chaves para uma definição. Um olhar do arranjo institucional nos conduz também para uma das formas de democracia: a democracia representativa.

A democracia representativa é aquela em que há a delegação de mandatos como decorrência do exercício da soberania popular através de processos eleitorais, para a tomada de decisão com alto grau de autonomia para aqueles que o detém.

Autores discutem a limitação da própria representatividade como caraterística desse conceito de democracia e suas implicações para que, em suas visões, suas contradições se acentuem, resultando em opostos às suas motivações iniciais. Nas palavras de Castello, Houtzager e Lavalle (2006):

\begin{abstract}
A representação política nas democracias contemporâneas sofreu transformações profundas no último quartel do século XX: partidos políticos de massa perderam sua centralidade como ordenadores estáveis das identidades e preferências do eleitorado; a personalização midiática da política sob a figura de lideranças plebiscitárias tornou-se um fenômeno comum; mudanças no mercado de trabalho tornaram instáveis e fluidas as grandes categorias populacionais outrora passíveis de representação por sua posição na estrutura ocupacional; e, se isso não bastasse, uma vaga de inovações institucionais tem levado a representação política, no Brasil e pelo mundo afora, a transbordar as eleições e o legislativo como lócus da representação, enveredando para o controle social e para a representação grupal nas funções executivas do governo. (CASTELLO, HOUTZAGER, LAVALLE, 2006, p. 49)
\end{abstract}

Representados não se veem com essa função por sentir que seus interesses não são os mesmos os quais os representantes expressam ou mesmo não concordam com decisões que por eles são tomadas. Um ponto que traz mais elementos na construção da democracia representativa vem de Bernand Manin, que afirma que o processo eleitoral não é um mecanismo suficiente para garantir que o bem-estar da coletividade seja alcançado ou mesmo defendido pelos representantes.

Para Manin, aliás, “o que está atualmente em declínio são as relações de identificação entre representantes e representados e a determinação da política pública por parte do eleitorado" (MANIN, 1995, p.3).

Nesse sentido, há o compartilhamento de uma percepção em que os representantes eleitos, tendo interesses objetivos e valores particulares, muitas vezes se comportam de maneira 
a buscar alcançar o bem estar dos cidadãos, situação que se estende aos partidos políticos. Esse cenário provoca, no mais das vezes, desconfiança nos regimes políticos democráticos devido a uma crise de valores que carece de consenso devido ao abalo das estruturas internas de suas instituições (GOYARD-FABRE, 2006).

A crítica da democracia representativa está presente pelo menos desde a década de 1990, por meio da investigação do filósofo Jürgen Habermas com a obra A Constelação PósNacional: Ensaios Políticos, publicado em 1998 (SILVA NETO, 2016), ocasião em que o autor identifica um esgotamento do seu núcleo utópico.

Já a partir de 1973, segundo Habermas (2002), em sua obra A Crise de Legitimação no Capitalismo Tardio, a crise nas sociedades ocidentais avançadas, devido à perda de adesão da opinião pública às regulações formalizadas e especializadas na ordem jurídica. Tal crise abre caminho para reflexões sobre a democracia participativa (SILVA NETO, 2016).

Em Mudança estrutural da esfera pública: Investigações sobre uma categoria da sociedade burguesa (HABERMAS, 2014), os temas "democracia" e "cidade" se aproximam, ainda que sem uma correlação explícita. Para o desenvolvimento da esfera pública, o autor aponta que foi necessário a criação e idealização de uma esfera autônoma ao Estado, a partir da burguesia, exigindo a prestação de contas pelo poder público.

Essa esfera autônoma ao Estado nasceu a partir da esfera privada cuja origem remonta às organizações laborais, aos clubes e às entidades sociais, organizações que cresceram juntamente com as cidades europeias no fim do período medieval.

A esfera pública, na perspectiva de uma teoria da democracia, não pode se limitar a perceber e identificar os problemas, ou seja, ser apenas um sistema de alarme social no âmbito da sociedade (HABERMAS, 2014), que segundo Silva Neto (2016), a sociedade civil:

\footnotetext{
“[...], não se vincula a uma perspectiva institucional, ligada ao Estado, ou econômica, que segrega segundo o critério do capital. A sociedade civil é uma intermediária entre o mundo da vida e a esfera pública, sendo que esta última como esfera pública política é capaz de tratar os ecos captados dos problemas sociais que se dá através dos movimentos, organizações e associações" (SILVA NETO, 2016, p. 118).
}

Devido à impossibilidade de acesso a bens materiais a todos, a estruturação moderna (burguesa) da esfera pública política tem suas limitações principalmente ao seu acesso por parte dos trabalhadores desprovidos de educação formal e de riqueza material. Desse modo a configuração inicial da esfera pública política passa a ser contrariada por: a) desqualificação do discurso político tradicional; b) deslocamento da questão democrática para o problema do sufrágio universal; c) o descrédito no poder da opinião pública; d) a pretensão da uniformidade 
que provocou o desrespeito pela diversidade e a questão da tolerância face à excessiva uniformidade de preocupação de opinião na esfera pública (SILVA NETO, 2016).

Segundo SILVA NETO (2016), Habermas reconhece a autodeterminação social e a postura dialógica no plano da publicidade moderna, considerando o formato plural e participativo dos elementos que compõem a opinião pública. E, diante desse quadro objetiva solucionar como é possível uma postura desvinculada da manipulação ideológica através da superação da expansão do interesse privado sobre o público e a desburocratização do Estado que através de suas diretivas perderam o "papel original de instrumento de defesa e garantia da sociedade" em que a "[...] formação da opinião pública e o crescimento dos meios de participação política ganham destacada centralidade nesse esquema" (SILVA NETO, 2016, p. 120), sendo a opinião pública atrelada aos argumentos sociais veiculados em meios de comunicação arraigados nos pressupostos do Estado democrático de direito acabam por legitimar o poder.

Nesse sentido os problemas da esfera pública estariam associados ao:

avanço da razão instrumental sobre o cotidiano das pessoas, num processo que se desenrola em várias frentes. A principal delas centra-se na já mencionada cultura de massas, cujos tentáculos vão desde a publicidade comercial à produção cultural (filmes, teatro, música), responsável por influenciar gostos, marcar tendências e direcionar o comportamento social, dirigido ao consumo e à atuação socialmente controlada, tendo como marca a docilidade social (SILVA NETO, 2016, p. 121)

Considera-se que a saída para os problemas da esfera pública está consolidada no uso da razão ou melhor de acuidade na utilização na utilização das informações divulgadas por diversos meios e a possibilidade do bom uso de tais informações no seio do debate público. Por fim, a força democrática da razão foi cristalizada pelas instituições sociais da publicidade através do agir dialógico de seus integrantes conferindo-lhe o estatuto de condição sine qua non da democracia (LAVALLE, 2002).

\section{CIDADES INTELIGENTES E DEMOCRACIA: REVISÃO SISTEMÁTICA DE LITERATURA}

Por meio de um processo de natureza qualitativa de revisão de literatura, transparente e reaplicável, a Revisão Sistemática de Literatura (RSL) segue critérios rigorosos. Baseia-se em evidências e tem como objetivo mapear, avaliar, identificar o território intelectual existente sobre um determinada questão ou tema de pesquisa (TRANFIELD et al., 2003) 
Este método foi escolhido justamente pelo seu rigor e possibilidade de controle das variáveis. Conforme os critérios estabelecidos para realização da RSL, os resultados desse estudo foram alcançados através de etapas, sendo elas: 1. Planejamento, 2. Condução da Revisão e 3. Divulgação dos Resultados. Cada etapa é composta por fases que correspondem aos processos executados durante toda a pesquisa; as etapas e fases desenvolvidas foram adaptadas de TRANFIELD et al (2003):

$\mathrm{Na}$ condução da revisão foi realizada uma revisão da literatura para definir "como se relaciona o conceito de cidade inteligente e democracia"; foram utilizados diversos estudos científicos que possuem citações na base Scopus da Elsevier.

Utilizamos a revisão de literatura como um processo de investigação inicial necessária para entender a construção do conceito de democracia e as definições existentes para cidades inteligentes, assim como deixar claro como podem ser agrupados em dimensões e categorias. Para o procedimento de análise dos dados foram determinados e aplicados os critérios de seleção e validação da amostra. Uma RSL se baseia em evidências científicas, e para tal é necessário atestar que elas estarão presentes na base de dados final para alcançar atendiam os objetivos da pesquisa.

Visando fortalecer a qualificação do método científico, os critérios de seleção e validação foram desenvolvidos e aplicados durante a execução da RSL. É fundamental distinguir e separar os documentos que se caracterizam como evidências (provas) das suposições (PETTICREW \& ROBERTS, 2008).

Como forma de atender ao rigor metodológico exigido em uma RSL e responder aos objetivos do estudo, as dimensões foram comparadas com os resultados que emergiram da Revisão da Literatura. O propósito foi colocar as provas em prática e garantir a cientificidade da pesquisa.

Para a coleta dos dados iniciais optamos por utilizar a plataforma científica Scopus, por se tratar do maior acervo de resumos e citações da literatura revisada por pares (SCOPUS, 2020), além de conter milhares de títulos de editores de todo mundo.

O protocolo para realização da coleta de dados utilizou-se dos seguintes parâmetros:

Em julho de 2020 realizamos a busca na Scopus utilizando os termos, "smartcit*" AND "democrac*". As aspas ("“) foram utilizadas para garantir que o sistema identificasse nos textos dos estudos e pesquisas os termos específicos desejados. Da mesma forma, utilizamos o asterisco $(*)$ para captar também as variantes do termo no plural e singular, neste caso podemos citar como exemplo as palavras: city, cities, democracy, democracies, democratic, etc. 
Outros parâmetros também foram utilizados: definimos que os termos de busca deveriam constar no título (TITLE), resumo $(A B S)$ e palavras-chave (KEY) dos estudos; desta forma o sistema identificou conteúdos que tratavam especificamente do tema de interesse.

Optamos também por utilizar apenas artigos científicos (DOCTYPE ((ar))) publicados na língua Inglesa (Language $(($ English $)))$. Por fim, determinamos o período das publicações; para tal consideramos relevante estudos dos últimos 10 anos; para inclusão no sistema utilizamos o filtro $(2010<2020)$.

A busca retornou com um total de 45 documentos: estes conteúdos foram publicados em 37 periódicos de diversas áreas do conhecimento e envolveram 88 pesquisadores das mais variadas nacionalidades. São 417 citações, conforme informações atualizadas na plataforma Scopus em julho de 2020.

Iniciamos a fase de análise dos dados definindo os critérios de seleção dos 45 documentos identificados. Conforme proposto por PETTICREW e ROBERTS, 2008 e TRANFIELD, DENYER \& SMART, 2003 este processo tem como objetivo separar os conteúdos científicos de outros que não sejam relevantes ou que não se caracterizem como evidências; para isto determinamos os critérios de inclusão e exclusão.

Como critérios de inclusão, foram considerados alguns pontos essenciais. Posto que a RSL deve ser baseada em evidências, selecionamos apenas artigos científicos, tendo em vista que passam por processos rigorosos de validação. Relevante determinar um período, nesse caso os últimos 10 anos, com o propósito de acompanhar o desenvolvimento e a evolução do tema até os dias atuais. A língua inglesa foi adotada como a língua franca da ciência mundial, com isso optou-se com selecionar artigo apenas neste idioma e utilizar estudos de diversas áreas do conhecimento, por se tratar de um tema multidisciplinar considerado fundamental para compor a amostra.

Assim como os critérios de inclusão, importante clarificar os critérios de exclusão, que para o objetivo colocado foram todos os conteúdos que não atendam aos critérios de inclusão, como por exemplo, estudos que não são artigos científicos ou que estão fora do período de publicação determinado.

Em julho de 2020 realizamos a leitura dos resumos dos 45 documentos da amostra inicial; após este processo foram excluídos 5 conteúdos que não atendiam aos critérios de seleção estabelecidos, restando 40 documentos para serem examinados.

Na continuidade do processo de análise dos dados passamos para a fase de validação da amostra; trata-se da avaliação da qualidade dos documentos restantes (PETTICREW \& ROBERTS 2006; TRANFIELD, et al 2003). Neste momento é necessário aferir se os artigos 
selecionados atendem às necessidades da pesquisa, para isso, devem responder às seguintes indagações: Os artigos que formam a base de dados da amostra fornecem evidências que respondem à questão de pesquisa? Os artigos que formam a base de dados da amostra atendem aos objetivos deste estudo? No mês de setembro de 2020 realizamos a leitura completa dos 40 documentos para validação da amostra; neste processo foram identificados quais artigos não atenderam as necessidades da pesquisa (1), sendo excluído da base de dados, restando 35 artigos para análise. Os estudos excluídos por critérios de seleção e validação estão disponíveis para consulta nos anexos deste artigo.

Por fim, estabelecemos uma amostra final com os documentos que passaram por todos os critérios de seleção e validação e permitiram a identificação das principais dimensões e categorias latentes abordadas nos estudos entre cidades inteligentes e democracia.

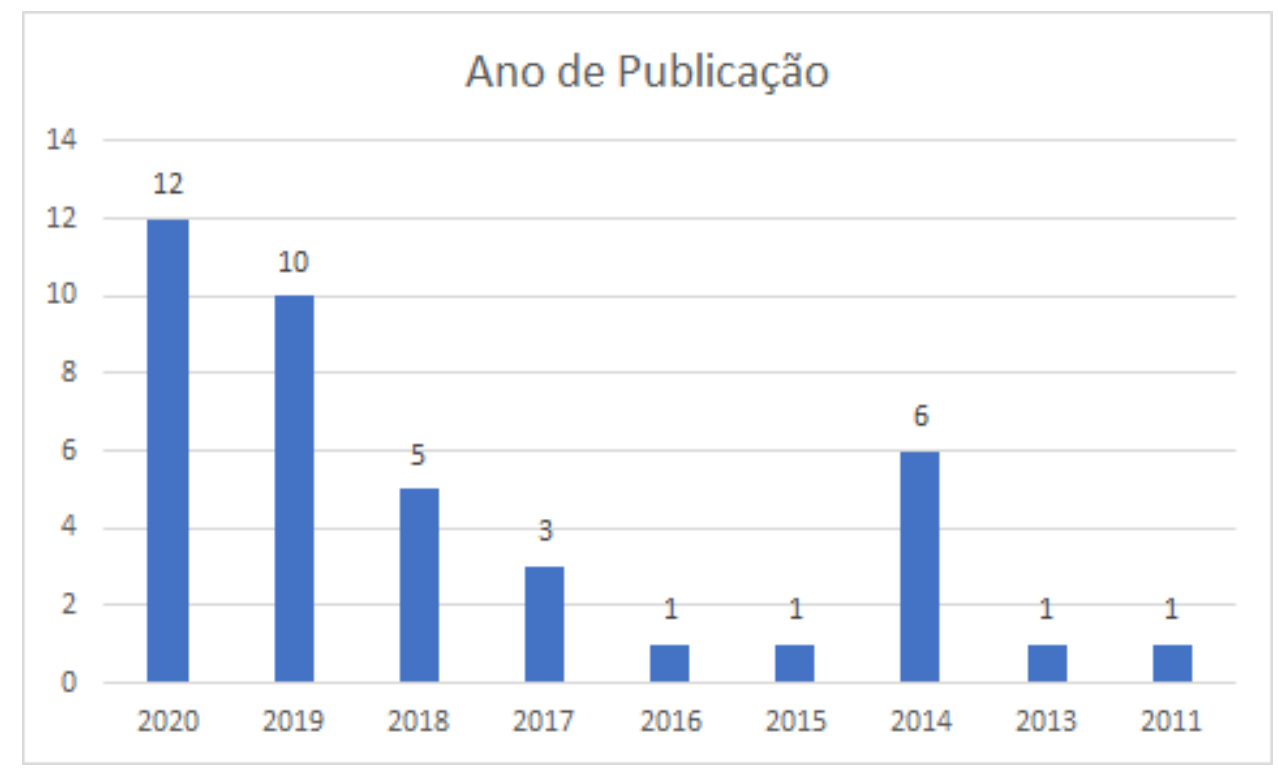

3. QUAIS CONCEITOS DE CIDADE INTELIGENTE E DEMOCRACIA ESTÃO EM DISCUSSÃO?

Como já explorado no item 1, a democracia é um conceito que vem sendo construído há tempos e, novamente com Schumpeter é"o arranjo institucional para se chegar a certas decisões políticas que realizam o bem comum, cabendo ao próprio povo decidir, através da eleição de indivíduos que se reúnem para cumprir-lhe a vontade." (SCHUMPETER, 1961, p.300). 
Dentro do conceito apresentando, há espaço para discussão de diversos conceitos presentes nele, como "bem comum", "povo", "eleição" e "vontade", o que demonstra a complexidade do conceito. Apesar da riqueza do debate sobre o conceito de democracia e quais seus caminhos, para o alcance do objetivo do artigo trabalharemos com a discussão do caráter institucional da democracia, também presente na definição de Schumpeter, e depois como ele se relaciona com o conceito de cidade inteligente.

Autores como DAHL (2005) e CASTELLS (2000), através de perspectivas diferentes, deram contribuições importantes para o debate. DAHL (2005) desenvolve a definição de democracia a partir de critérios de institucionalização e o conceito de Poliarquia que avança no entendimento dos regimes democráticos, acrescentando aspectos para análises deles.

Dahl se utiliza de critérios mínimos para definir um regime democrático, através da definição de oportunidades que devem ser traduzidas em garantias institucionalizadas: oportunidade de formular suas preferências; oportunidade de expressar essas preferências e oportunidade de ter consideradas igualmente essas preferências na conduta do governo. Para cada uma das oportunidades, o autor lista as garantias necessárias, como podemos ver na tabela abaixo:

\section{Tabela 1}

\section{Alguns requisitos de uma democracia para muitas pessoas}

Para a oportunidade de:

I. Formular preferências

\section{São necessárias as seguintes garantias institucionais:}

1. Liberdade de formar e aderir a organizações

2. Liberdade de expressão

3. Direito de voto

4. Direito de líderes políticos disputarem apoio

5. Fontes alternativas de informação

II. Exprimir preferências

1. Liberdade de formar e aderir a organizações

2. Liberdade de expressão

3. Direito de voto

4. Elegibilidade para cargos políticos

5. Direito de líderes políticos disputarem apoio

6. Fontes alternativas de informação

7. Eleições livres e idôneas
III. Ter preferências igualmente consideradas na conduta do governo
1. Liberdade de formar e aderir a organizações

2. Liberdade de expressão

3. Direito de voto

4. Elegibilidade para cargos públicos

5. Direito de líderes políticos disputarem apoio

5a. Direito de líderes políticos disputarem voto

6. Fontes alternativas de informação

7. Eleições livres e idôneas

8. Instituições para fazer com que as políticas governamentais dependam de eleições e de outras manifestações de preferência. 
Nota: (Dahl, Poliarquia: Participação e Oposição, 2005, p. 27)

$\mathrm{O}$ autor reforça a importância da institucionalidade da democracia, indo para além da discussão de conceitos abstratos. Para o autor os regimes podem ser observados como hegemonias fechadas, hegemonias inclusivas, oligarquias competitivas ou poliarquias. Com a importância da institucionalidade, Dahl ajuda a entender que a alta disputa pelo espaço de poder combinada com alta participação social permite a construção de regimes democráticos avançados, as chamadas poliarquias. A poliarquia é definida como os arranjos institucionais que permitem que posições distintas participem do processo político. Para o autor, os regimes podem ser observados como hegemonias fechadas, hegemonias inclusivas, oligarquias competitivas ou, democracias mais avançadas, as poliarquias.

Combinando a importância da participação social trazida por Dahl com o conceito de sociedade em rede de CASTELLS (2000), podemos trazer elementos que ajudam a entender a sociedade após a revolução tecnológica das redes nas comunicações. Para Castells, o impacto da tecnologia nas comunicações e nas relações humanas muda a sociedade. O impacto do entendimento da sociedade que atua através de redes nos leva a rever a forma como são construídas as relações sociais. Castells afirma que o poder em uma sociedade em rede é exercido através das redes, e seus atores atuando, ora como "programadores" das redes, alterando condições e ações, ora como "switches", conectando e desconectando as redes. Esse conceito traz a complexidade das relações da sociedade e a necessidade de considerar a diversidade de atores e papéis, além dos tradicionais como o poder executivo, os legisladores e o capital (CASTELLS, 2011).

No campo da filosofia do direito, a discussão sobre a tomada de decisão e a construção de arcabouços jurídicos, o filósofo canadense Charles Taylor duvida da capacidade do modelo liberal, especialmente da tradição rousseauniana, em incluir todos nesse processo. Em um mundo marcado pela diversidade dos atores e culturas, a hegemonia de grandes segmentos sociais acaba por marginalizar outros no processo de tomada de decisão (TAYLOR, 1994).

Taylor traz que a democracia lançou a política de reconhecimento igualitário onde os diferentes buscam através de um conjunto de regras iguais e aplicáveis a todos, o reconhecimento, através da discussão na esfera pública, das diversas culturas.

O espaço onde acontece o processo democrático, ou suas esferas, traz à tona ideias como a de Habermas. Para o autor, esfera pública é: uma rede adequada para a comunicação de conteúdo, tomadas de posição e opiniões; nela os fluxos comunicacionais são filtrados e 
sintetizados a ponto de se condensarem em opiniões públicas enfeixadas em temas específicos. (HABERMAS, 2003, p. 92).

Trazendo para o debate as relações entre as esferas públicas e democracia em Habermas, Levy afirma que o filósofo alemão contribui com um:

pensamento que se consagra pelas possibilidades de interpretação que oferece num mundo em que esfera pública e democracia se encontram numa encruzilhada, em que se multiplica a supressão das vozes dos atores sociais e o acirramento da colonização do mundo da vida, em sua face econômica, sobre as formas de participação e deliberação que a democracia permite. (LEVY, 2008, p. 237)

Para interligar a discussão da democracia com o conceito de cidades inteligentes, é necessário buscar a origem da construção do conceito e qual a necessidade levou "inteligente" a ser integrado com o conceito de "cidade".

A discussão sobre a definição do conceito de cidade inteligente nos leva ao início da década de 90, momento em que a base para essa definição se colocava nas tecnologias desenvolvidas levando em consideração o papel da infraestrutura de comunicação, especialmente o desenvolvimento da Internet (CARAGLIU et al., 2011, p. 69).

A ampliação do entendimento como além da infraestrutura de comunicação, deslocou a discussão de cidade inteligente em outro patamar, como o Centre of Regional Science da Viena Universityof Technologyque classificou como seis as dimensões para a análise com vistas a identificar cidade médias europeias possíveis de serem classificadas. As dimensões se colocamcomosmart economy, smart people, smart governance, smart mobility, smart environment e smart living (GIFFINGER et al., 2007, p. 11)

Com o desenvolvimento do tema, autores aprofundaram sua definição, ampliando o entendimento do que pode ser chamado de cidade inteligente. Caragliu, Bel Bo e Nijkamp trouxeram importante contribuição ao discutir o desenvolvimento das cidades na Europa, e apesar da dificuldade na utilização do conceito, os autores definem em seu trabalho cidade inteligente como:

(..) when investments in human and social capital and traditional (transport) and modern (ICT) communication infrastructure fuel sustainable economic growth and a high quality of life, with a wise management of natural resources, through participatory governance. (CARAGLIU et al., 2011, p. 70)

Outros autores reconhecem a influência do conceito de cidade inteligente na discussão sobre o desenvolvimento do futuro do urbanismo. Hollands (2008) problematiza a amplitude da aplicação do termo smart dentro do contexto do desenvolvimento urbano. Para além da aplicação da tecnologia, o autor chama atenção para as contradições na implementação dos diversos modelos de cidades inteligentes, que podem ter aplicação de um conceito high tech da 
cidade empreendedora de JESSOP (1997). Hollands buscar trazer o elemento de justiça social para o debate, com o objetivo de construir, para além da tecnologia, cidades inteligentes mais progressistas e inclusivas.

Para alcançar esse objetivo, Hollands propõe que a população e o capital humano estejam presentes na equação do desenvolvimento das cidades, além da questão tecnológica, que lembrando Raymond Willians, nunca é neutra. Além da tecnologia estar a serviços das populações mais vulneráveis, e não o contrário, Hollands também coloca a necessidade de equilibrar desenvolvimento econômico e sustentabilidade. O autor ressalta a importância de incluir contribuições dos diversos grupos que compõem uma cidade, dando possibilidade, assim, para uma cidade inteligente progressista.

Mais recentemente, DEAKIN e LEYDESDORFF trouxeram ao debate o conceito de Triple-Helix Model para as cidades inteligentes (DEAKIN \& LEYDESDORFF, 2011). Nesse modelo as cidades são consideradas como uma rede entre 1) o capital intelectual das universidades, 2) a criação de riquezas pela indústria e 3) governo democrático da sociedade civil e através da interação entre os três tópicos se dará o potencial da cidade inteligente.

Adentrando na discussão na literatura sobre como a dimensão da democracia interage em uma cidade inteligente, VIITANEN e KINGSTONN (2013) trazem à discussão como o foco no uso da tecnologia impacta a construção da democracia nas cidades inteligentes. Ao observar o cidadão num papel de consumidor de tecnologia, os autores afirmam que o cerne na implantação de ICT's transforma a democracia em mais um produto a ser consumido pelos “cidadãos-clientes" da cidade, trazendo impactos no seu desenvolvimento. O centro do desenvolvimento como mercado da democracia, resulta em uma cidade menos resilientes em relação ao seu futuro social e riscos climáticos (VIITANEN \& KINGSTON, 2013, p. 814).

Para Deakin, a integração trazida pelo modelo Tripe-Helix Model traz as cidades inteligentes para além de ser um slogan de marketing de empresas detentoras da tecnologia, dando a oportunidade de integrar conhecimento, geração de riquezas e oportunidade de participação direta da sociedade nas tomadas de decisão (DEAKIN, 2014, p. 9). Dialogando com CARAGLIU, GIFFINGER e, principalmente, HOLLANDS, DEAKIN reforça a importância da democracia para que as cidades inteligentes alcancem o objetivo da chamada thirdmission agenda, a integração entre conhecimento e riquezas, porém gerando resultados culturais, sociais e ambientais.

A tecnologia aplicada à democracia, através do seu uso para o exercício na tomada de decisão ou na coleta de opiniões, é também relacionada no desenvolvimento das cidades inteligentes. A e-governance concentra esse conceito e é explorada por WALTERS. Para o 
autor a tecnologia age como força centrífuga e é equilibrada pela interação humana no espaço físico, que atua como força centrípeta (Walters, 2011, p. 199).

Para o autor a inclusão de temas locais é ilustrada através de um estudo de caso da cidade americana de Beaufort. $\mathrm{O}$ uso da tecnologia através de formulários eletrônicos para basear o planejamento da cidade, mitigou a preocupação da exclusão que pode causar o uso intensivo da tecnologia nas cidades (WALTERS, 2011, p. 216).

Soluções como a defendida por Walters são criticadas por autores, como TENNEY e SIEBER, que veem o risco de cidadãos serem tratados como "sensores" no processo de planejamento de uma cidade (TENNEY \& SIEBER, 2016). A crítica dos autores se dá pela postura passiva que o uso de tecnologia pode causar nos cidadãos, como no compartilhamento de dados de localização para a definição de uma política pública.

\section{A DEMOCRACIA É RELEVANTE PARA UMA CIDADE INTELIGENTES?}

Diante da revisão da literatura realizada na seção anterior, os resultados dos artigos selecionados através da metodologia aplicada foram divididos em quatro categorias baseados em duas dimensões: relevante $(\mathrm{R})$ ou não relevante $(\mathrm{N})$ e hipotética $(\mathrm{H})$ ou observada $(\mathrm{O})$, assim como também foi realizada na RSL realizada por Lim, Edelenbos e Gianoli ao estudarem o desenvolvimento das cidades inteligentes (LIM et al., 2019).

Entre as dimensões foram considerados relevantes os estudos que demonstraram a relação entre cidades inteligentes e democracia como importante na construção urbana (R) e as não relevantes $(\mathrm{N})$ os que não encontraram importância na mesma. Na mesma forma, a dimensão hipotética $(\mathrm{H})$ se dá no campo da especulação ou na expectativa de mudanças, enquanto a observada $(\mathrm{O})$ se refere quando há afirmações feitas através de estudos empíricos.

Realizada a leitura e classificação dos artigos selecionados, chegou-se ao resultado que a dimensão classificada como "relevante" (R) corresponde a 74\% $(n=26)$ da base dos artigos selecionados. O restante foi classificado na dimensão "não relevantes" (N) não encontrando relação do conceito de cidades inteligentes com democracia, correspondendo a $26 \%(\mathrm{n}=9)$ da seleção.

Aprofundando os dados, dentro da dimensão "relevante" há igualdade na distribuição nas categorias "hipotético" (HR) e "observado" (OR), 50\% (n=13) para cada um, o mesmo não acontece na dimensão "não relevante". Nessa dimensão a distribuição realizada ficou em 33\% $(n=3)$ para a categoria "hipotética/não relevante" $(\mathrm{HN})$ e $66 \%(\mathrm{n}=6)$ para "observado/não relevante" $(\mathrm{ON})$. 
A imagem 1 mostra a distribuição dos artigos:

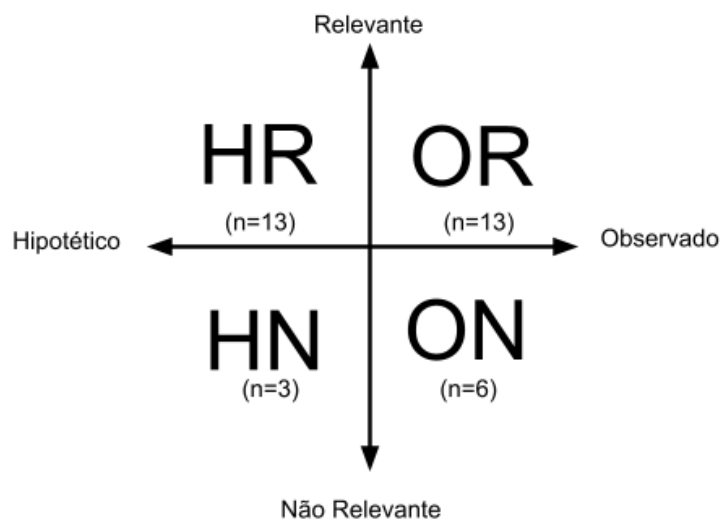

Também demonstrado na tabela abaixo:

\begin{tabular}{|l|l|c|}
\hline Categoria & \multicolumn{1}{|c|}{ Dimensão } & $\begin{array}{c}n \text { do } \\
\text { conjunto }\end{array}$ \\
\hline Hipotético & Relevante & 13 \\
\hline Observado & Relevante & 13 \\
\hline Hipotético & Não relevante & 3 \\
\hline Observado & Não relevante & 6 \\
\hline
\end{tabular}

O gráfico abaixo demonstra a distribuição das categoriais e a participação no geral de cada uma:

\section{Dimensões e Categorias}

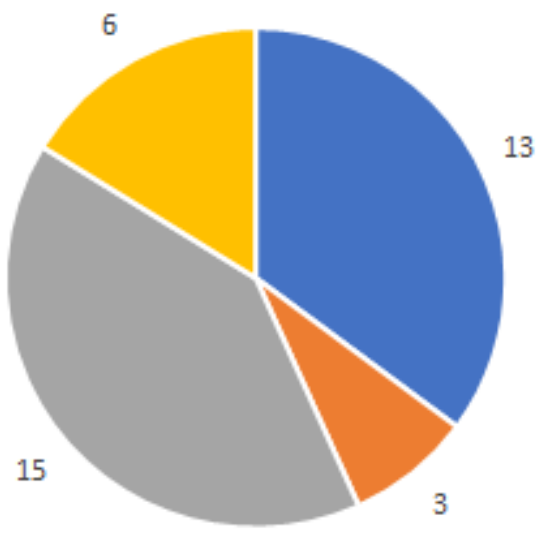


Os resultados demonstram que dentro da seleção dos artigos e da metodologia escolhida,uma relação consistente entre cidade inteligente e democracia se demonstra majoritária quando comparada aos artigos que não encontram evidência sobre essa relação.

Os dados também demonstram que apesar da quantidade de artigos classificados como "não relevante" ser menor, quando olhado de forma separada, a participação da categoria "observados" se mostra mais presente, proporcionalmente, do que na dimensão majoritária.

Essa ponderação pode nos levar a uma tendência de que a observação através de um estudo empírico reduz a relevância da relação cidade inteligente e democracia, porém os dados não são suficientes para uma afirmação. Estudos posteriores podem aprofundar a verificação desta tendência.

\section{CONCLUSÃO}

A despeito da incipiência da literatura que correlaciona cidades inteligentes à democracia, esta é uma discussão com múltiplas interfaces e possibilidades de aproximação.

Conforme avança o debate sobre as cidades inteligentes, considerando que seu alcance é maior do que a mera relação entre território, políticas públicas e tecnologia, parece certo que aspectos relacionados à governança e, por conseguinte, à democracia, sejam paulatinamente incorporados.

Tal medida importará, como dito, na aproximação entre inteligência e democracia enxergando nessa relação inúmeras possibilidades para lidar com os conflitos próprios das relações sociais que têm lugar na cidade. Vale dizer, haveria uma inteligência em adotar as formas institucionais e legais típicas da democracia como mecanismo apto à mediação dos conflitos existentes na cidade e, com isso, contribuir para uma vida urbana mais compatível com os propósitos de uma maior qualidade de vida para seus habitantes.

\section{REFERÊNCIAS BIBLIOGRÁFICAS}

CARAGLIU, Andrea, DEL BO, Chiara, \& NIJKAMP, Peter. (2011). Smart Cities in Europe. Journal of Urban Technology, 18(2), 65-82. http://dx.doi.org/10.1080/10630732.2011.601117

CASTELLS, Manuel. (2000). A Sociedade em Rede. Paz e Terra.

CASTELLS, Manuel. (2011). A Network Theory of Power. International Journal of Communication, 773-787. 
DAHL, Robert. (2005). Poliarquia: Participação e Oposição (C. Paciornik, Trans.). Universidade de São Paulo.

DEAKIN, Mark. (2014). Smart cities: the state-of-the-art and governance challenge. Triple Helix, 1(7), 1-16. 10.1186/s40604-014-0007-9

DEAKIN, Mark, \& LEYDESDORFF, Loet. (2011). The Triple-Helix Model of Smart Cities: A Neo-Evolutionary Perspective. Journal of Urban Technology, 18(2), 53-63. 10.1080/10630732.2011.601111

GIFFINGER, Rudolf, et al (2007). Smart Cities: Ranking of European Medium-Sized Cities. Centre of Regional Science (SRF), Vienna University of Technology.

GOYARD-FABRE, Simone. O que é Democracia? São Paulo: Martins Fontes, 2003

HABERMAS, Jürgen. (2002). A Crise de Legitimação no Capitalismo Tardio. Biblioteca Tempo Universitário 60.

HABERMAS, Jürgen. (2003). Direito e Democracia (F. Siebeneichler, Trans.; Vol. 2). Biblioteca Tempo Brasileiro.

HABERMAS, Jürgen. (2014). Mudança estrutural da esfera pública: Investigações sobre uma categoria da sociedade burguesa. São Paulo: EditoraUnesp

HOLLANDS, Robert. (2008). Will the real smart city please stand up? Intelligent, progressive or entrepreneurial? City, 12 (3), 303-320. 10.1080/13604810802479126

JESSOP, Bob. (1997). The entrepreneurial city: re-imagining localities, redesigning economic governance or restructuring capital. In Nick. Jasson\&Sussane. McGregor (Eds.), Transforming Cities. (pp. 28-41). Routledge.

LAVALLE, Adriá Gurza. Jürgen Habermas e a virtualização da publicidade.In: Margem, 16. São Paulo: Margem, 2002.

LEVY, Wilson. (2008, jan/jun). As relações entre esfera pública e democracia no pensamento de Jürgen Habermas. Direito, Estado e Sociedade, 32, 219-238.

LIM, Yirang, EDELENBOS, Jurian, \& GIANOLI, Alberto. (2019). Identifying the results of smart city development: Findings from systematic literature review. Cities, 95. 10.1016/j.cities.2019.102397

MANIN, Bernard; PRZEWORSKI, Adam; STOKES, Susan C. Eleições e Representação. In: Lua Nova n. ${ }^{\circ}$ 67. São Paulo: 2006.

PETTICREW, Mark \& ROBERTS, Helen (2008). Systematic reviews-do they 'work' in informing decision-making around health inequalities? Health economics, policy, and law, 3(2). $10.1017 / \mathrm{S} 1744133108004453$

QUIRINO, G., \& STOROPOLI, José Eduardo. (2020 (No prelo)). Planejamento de Cidade Inteligentes (Título Provisório).

SCHUMPETER, Joseph. (1961). Capitalismo, Socialismo e Democracia (R. Jungmann, Trans.). Fundo da Cultura. 
SILVA NETO, Wilson Levy Braga da. Uma teoria do direito à cidade: reflexões interdisciplinares. 2016. 239 f. Tese (Doutorado em Direito) - Programa de Estudos Pós-Graduados em Direito, Pontifícia Universidade Católica de São Paulo, São Paulo, 2016.

TAYLOR, Charles (1994). A política do reconhecimento. In Multiculturalismo (pp. 45-94). Instituto Piaget.

TENNEY, Matthew; SIEBER, Renee. (2016). Data-Driven Participation: Algorithms, Cities, Citizens, and Corporate Control. Urban Planning, 1(2), 101-113. 10.17645/up.v1i2.645

TRANFIELD, David; DENYER, David; SMART, Palminder. (2003). Towards a Methodology for Developing Evidence-Informed Management Knowledge by Means of Systematic Review. British Journal of Management, 14, 207-222.

VIITANEN, Jenni; KINGSTON, Richard (2013). Smart cities and green growth: outsourcing democratic and environmental resilience to the global technology sector. Environment and Planning, 46, 803-819. 10.1068/a46242

WALTERS, David (2011). Smart cities, smart places, smart democracy: Form-based codes, electronic governance and the role of place in making smart cities. Intelligent Buildings International, 3(3), 198-218. 10.1080/17508975.2011.586670

Trabalho recebido em 01 de outubro de 2021 Aceito em 01 de novembro de 2021 